\title{
Early Massive Bleeding after Endoscopic Ligation for Junctional Varices
}

We report an early and life-threatening hemorrhage directly related to endoscopic variceal ligation (EVL) of junctional varices.

A 57-year-old black man with cirrhosis (Child B) caused by hepatitis B and D was evaluated after three sessions of EVL indicated for secondary prevention of variceal bleeding. Elective upper endoscopy under sedation revealed grade 2 esophageal varices and junctional varices. Band ligation was done using the multishot ligation device (Speedband, Microvasive Boston Scientific Corporation, Watertown, Massachusetts, USA) with the placement of three bands on esophageal varices and two bands on junctional varices without overtube. Ten hours after EVL, rapid collapse and massive upper gastrointestinal bleeding occurred. Intubation by balloon tamponade (Sengstaken-Blakemore tube), did not achieve hemostasis. The source of bleeding was not identified by an endoscopic examination performed in theater. The patient underwent an emergency paraesophagogastric devascularization which failed to stop the bleeding. The gastrotomy performed revealed an active pulse bleeding from a $10-\mathrm{mm}$ ulceration located $2 \mathrm{~cm}$ below the gastroesophageal junction along the lesser curve. Its suture achieved hemostasis. One elastic $\mathrm{O}$ ring was found in the stomach area. The patient was treated with omeprazole $20 \mathrm{mg}$ daily, recovered, and was discharged from hospital. No recurrence of hemorrhage occurred during a 6 month follow-up and eradication of varices was achieved.

Complications directly related to EVL are uncommon [1-3]. We observed a bleeding from an unusual ulceration after EVL [4], probably deep enough to injure a submucosal arterial vessel, as suggested by its pulsatility and the failure of para-esophagogastric devascularization to stop the bleeding. This ulceration was located at the same spot as the banding performed ten hours previously and did not correspond to a Dieulafoy's ulcer. Our report suggests a benefit from monitoring patients during the first 24 hours after EVL for junctional varices.

G. Savoye, P. Hochain, G. Riachi, M. Scotté, S. Hervé, B. Fraleu-Louer, A. Chiron. P. Ducrotté

The Digestive Tract Research Group, Rouen University Hospital, Rouen, France

\section{References}

1. Laine L, Cook D. Endoscopic ligation compared with sclerotherapy for treatment of esophageal variceal bleeding. A meta-analysis. Ann Intern Med $1995 ; 123: 280-7$

2. Van Stiegmann G. Endoscopic ligation: now and the future. Gastrointest Endosc 1993; 39: 203-5

3. Nijhawan S, Rai RR, Nepalia S, et al. Natural history of postligation ulcers. Am J Gastroenterol 1994; 89: 2281-2
4. Young MF, Sanowski RA, Rasche R. Comparison and characterization of ulcerations induced by endoscopic ligation of esophageal varices versus endoscopic sclerotherapy. Gastrointest Endosc 1993; 39: 119-22

\section{Corresponding Author}

P. Hochain, M.D.

Groupe de Recherche sur

l'Appareil Digestif

Hôpital Charles Nicolle

1 rue de Germont

76031 Rouen Cedex, France

Fax: $\quad+33(2) 35151623$

E-mail: Gastro.Entero.Nutrition@ chu-Rouen.fr 